\title{
LA INTERPRETACIÓN EN EL DERECHO TRIBUTARIO
}

\author{
THE INTERPRETATION IN TAX LAW
}

\author{
Ángel Marco Chávez Gonzales \\ Universidad ESAN, Perú \\ https: / / orcid.org/0000-0002-5732-2233
}

\section{Resumen}

Las controversias fiscales impugnadas se originan en parte en las distintas interpretaciones de las normas tributarias que aplican la Administración Fiscal y los contribuyentes, de ahí que este tema sea de interés académico. Para abordarlo, se ha recurrido a la doctrina y, desde un punto de vista práctico, a las resoluciones del Tribunal Fiscal y a las sentencias de casación del Poder Judicial. Este artículo comienza mostrando lo que significan en números las controversias tributarias; luego trata la interpretación de la norma tributaria, con referencia a la aproximación apriorística del intérprete, que es lo que se conoce como criterios generales de interpretación. A continuación, el artículo se ocupa de los métodos de interpretación; seguidamente se verán los apotegmas de interpretación, que son argumentos jurídicos aceptados a los cuales el intérprete recurre. El artículo finaliza con la analogía, la interpretación excesiva de la norma y la interpretación de la desgravación tributaria.

\begin{abstract}
Tax controversies in part are originated by the different interpretations of the tax regulations between tax administration and taxpayers, so the issue of the interpretation of the tax regulations is of academic interest for this reason we have resorted to the doctrine and from a practical point of view to the resolutions of the Tax Court and the judgments of the Supreme Court. This article begins showing what tax controversies mean in numbers; then referring
\end{abstract}


to the a priori approach of the interpreter, known as general interpretation criteria; also we will discuss the methods of interpretation; after we will see the apothegms of interpretation, which are topical arguments of fairly general acceptance; finalizing the article with the analogy, the excessive interpretation of the rule and the interpretation of the tax relief.

Palabras clave: interpretación de las normas tributarias, criterios interpretativos, métodos de interpretación, apotegmas de interpretación, analogía.

Keywords: interpretation of tax rules, interpretive criteria, methods of interpretation, interpretation apothegms, analogy.

\section{Introducción}

El tributarista Armando Zolezzi Möller afirma:

... en caso de duda la Administración Tributaria debía resolver a favor del fisco, toda vez que el contribuyente tiene medios de defensa y puede ir a instancias para que analicen su posición, como el Tribunal Fiscal (TF) o el Poder Judicial. No ocurriría lo mismo si se resolviera en contra del fisco, ya que - desde su perspectiva - la misma Administración Tributaria no podría poner en cuestión su acto administrativo" ${ }^{\prime 1}$.

Este comentario refleja lo que en la práctica sucede con los órganos resolutores de la administración tributaria al interpretar y aplicar las normas tributarias en las controversias fiscales, así como al ejercer su facultad de calificación jurídica de los hechos que recoge el informe Conflictividad en cifras del Estudio Zuzunaga, Assereto y Zegarra Abogados². Este ha sido elaborado a partir de la revisión del total de resoluciones del Tribunal Fiscal y de casación del Poder Judicial publicadas de enero a julio de 2020; y de la deuda gestiona-

1 Armando Zolezzi Möller, «Interpretación de la norma tributaria: ¿en los beneficios tributarios in dubio contra fiscum o in dubio pro fiscum?», Análisis tributario, (2010): 6.

2 Zuzunaga, Assereto \& Zegarra abogados, Conflictividad en cifras Z\&A 2020 (Lima: Zuzunaga, Assereto \& Zegarra abogados, 2020). 
da por la Sunat al 31 de diciembre de 2020. El informe, entre otras conclusiones, señala (ver figura y cuadro):

1. La deuda tributaria administrada por la Sunat al 31 de julio de 2020 asciende a S/ 120,677,000 millones, mientras que el presupuesto nacional (recursos ordinarios) del 2018 al 2021 es menor que dicha suma en cada uno de estos años.

2. El33\% de la deuda tributaria se encuentra impugnada; esto es S/ $39,823,410$ millones ( $1 \%$ en reclamación, $24 \%$ en apelación y $8 \%$ en proceso judicial).

3. El $67 \%$ de la deuda tributaria no se encuentra impugnada, sino en cobranza por la Sunat: S/ 80853590 .

4. En el $61 \%$ de estos casos fue la Sunat la que inició el proceso judicial.

5. Se comprueba que no es cierto que sean los contribuyentes quienes «judicializan el conflicto tributario».

\section{Deuda tributaria enero-julio 2020}

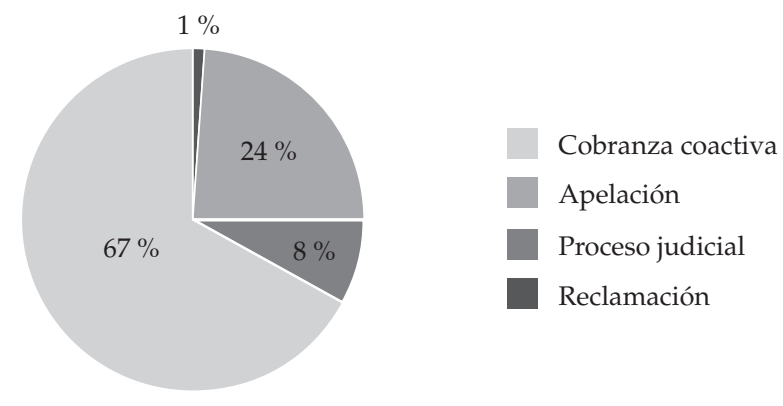

\begin{tabular}{|r|c|c|}
\hline Concepto & Monto (millones S/) & Porcentaje \\
\hline Deuda impugnada & $39,823,410$ & \\
Reclamación & $1,206,770$ & 1 \\
Apelación & $28,962,480$ & 24 \\
Proceso judicial & $9,654,160$ & 8 \\
Deuda en cobranza coactiva & $80,853,590$ & 67 \\
\hline Total & $\mathbf{1 2 0 , 6 7 7 , 0 0 0}$ & $\mathbf{1 0 0}$ \\
\hline
\end{tabular}


En virtud de estas cifras, el tema de la interpretación de las normas tributarias resulta de particular interés. Para tratar el tema, hemos recurrido a la doctrina y, desde un punto de vista práctico, a las resoluciones del Tribunal del Fiscal y a las sentencias de casación del Poder Judicial.

Este artículo será abordado según los tres componentes de Rubio Correa ${ }^{3}$ sobre interpretación jurídica: la aproximación apriorística del intérprete, consistente en lo que se conoce como criterios generales de interpretación; los mecanismos operativos de interpretación jurídica generalmente aceptados, conocidos como métodos de interpretación; y los apotegmas de interpretación, que son argumentos tópicos de aceptación bastante generalizada. Finaliza el artículo con la analogía, la interpretación excesiva de la norma y la interpretación de las desgravaciones tributarias.

\section{La interpretación jurídica y los métodos de interpretación admitidos por el Derecho según la Norma VIII del Título Preliminar del Código Tributario}

La interpretación jurídica es la actividad intelectual que tiene por objeto averiguar y establecer el significado o alcance que debe asignarse a las normas, es decir, determinar qué dice el derecho, sobre todo en aquellos casos en los que la norma tributaria no es clara, se contradice o cuyo contenido es lagunoso ${ }^{4}$. Esto puede deberse a un déficit del lenguaje empleado en la norma, términos ambiguos, imprecisos, proposiciones mal construidas sintácticamente ${ }^{5}$; o bien puede tratarse de una norma que en abstracto se percibe indiscutiblemente clara, pero que resulta siéndolo muy poco en un caso concreto, haciéndonos dudar de sus alcances o de su aplicabilidad al caso en cuestión 6 .

3 Marcial Rubio Correa, El sistema jurídico: introducción al derecho, 10. ${ }^{a}$ ed. (Lima: Fondo Editorial PUCP, 2011), 23.

4 Israel Santos Flores, «La interpretacion de la norma tributaria», en Manual de derecho fiscal, coord. Gabriela Ríos Granados (México: Universidad Nacional Autónoma de México, 2020), 62, https://archivos.juridicas.unam.mx/www/bjv/libros/13/6278/5a.pdf

5 Alberto Tarsitano, «Interpretacion de la ley tributaria», en Tratado de tributacion, derecho tributario, vol. 1, dir. Horacio García Belsunce (Buenos Aires: Editorial Astrea, 2003), 430. http://albertotarsitano.com/interpretacion/7interpretaciondelaleytributaria.pdf

6 Rubio Correa, El sistema jurídico, 222. 
Otra concepción señala que interpretar es una actividad intelectual que construye, crea, produce el contenido, el sentido y el alcance de las reglas jurídicas de manera distinta de lo que siempre proclamó para hacerlos incidir en un caso particular ${ }^{7}$; significa construir los contenidos significativos de los enunciados o frases prescriptivas atribuyendo valores a los símbolos, esto es, adjudicarles significaciones y, por medio de ellas, referencias a objetos para, en última instancia, ordenarlos en la forma de normas jurídicas, entendidas como estructuras categoriales construidas epistemológicamente por el intérprete a partir de las significaciones que la lectura de documentos despierta en su espíritu ${ }^{8}$.

Desde el punto de vista planteado en el presente artículo, interpretar no se limita solo a descubrir el significado o lo que quiere decir el texto oscuro de la norma, sino también a recrear su significado o el sentido que se hallaba oculto en el texto cuando se aplica a un caso concreto.

Al aplicar las normas tributarias podrán usarse todos los métodos de interpretación admitidos por el derecho, según señala el primer párrafo de la Norma VIII del Título Preliminar del Código Tributario. Aparentemente se trata de una precisión poco relevante, ya que, si una norma tributaria requiere interpretarse, es lógico que deban utilizarse los métodos de interpretación admitidos por el derecho. Se justifica, sin embargo, porque, de un lado, equipara las normas tributarias con las demás normas legales en cuanto al uso de los métodos de interpretación, pues se creía que las normas tributarias debían tener métodos de interpretación especiales ${ }^{9}{ }^{10}$. Por otra parte, termina con la tendencia de aplicar criterios de interpretación extrajurídicos y apriorísticos

7 Paulo de Barros Carvalho, Curso de derecho tributario (Lima: Grijley, 2012), 125, 130.

8 Paulo de Barros Carvalho, «La interpretacion en materia tributaria», Revista de Derecho, n. ${ }^{\circ}$ 4 (enero 2009): 38-42, https://revistas.ucu.edu.uy/index.php/revistadederecho/article/ view $/ 823 / 825$

9 La corriente autonomista del derecho tributario llegó al extremo de sostener que las leyes tributarias tenían que interpretarse de acuerdo con el método propio del derecho tributario, que se basa en consideraciones económicas. Luis Alberto Araoz Villena, «La Interpretación económica de las leyes tributarias y la calificación de los hechos imponibles por su de los hechos imponibles por su contenido económico», Revista del Instituto Peruano de Derecho Tributario, n. ${ }^{\circ}$ 23 (diciembre 1992): 71.

10 Luis María Cazorla Prieto, Derecho financiero y tributario: parte general (Navarra: Thomson Reuter Arazandi, 2000), 146. 
(contra fiscum ${ }^{11}$ o pro fiscum ${ }^{12}$ ) elaborados antiguamente en un contexto en el que los tributos provocaban rechazo en los ciudadanos y se consideraban atentatorios contra la libertad individual y económica.

Así, el derecho tributario no es un conjunto de normas aisladas o de excepción; se trata, en cambio, de normas que se funden en un mismo nivel con la totalidad del ordenamiento ${ }^{13}{ }^{14}$; por ello deben ser interpretadas utilizando los mismos métodos de interpretación del derecho común.

Según la clasificación de Savigny, los elementos por interpretar de la ley son:

a) El gramatical, relativo a la semiótica, la sintaxis y la pragmática del lenguaje, así como al conocimiento del lenguaje jurídico.

b) El lógico, que articula las reglas que forman todo pensamiento.

c) El histórico, referido al contexto que acompañan a la ley en su vigencia.

d) El sistemático, factor de unidad e integración de normas e instituciones dentro del derecho ${ }^{15}$.

Desde la perspectiva de Carvalho, interpretar el discurso prescriptivo del derecho es recorrer tres planos:

a) El sintáctico, referido a la disposición y colocación de las palabras en la frase normativa, la estructura normativa, el lazo condicional que une la hipótesis al consecuente, con lo cual opera la interpretación literal y lógica.

b) El semántico, que corresponde al lenguaje jurídico, las acepciones, el sentido, el significado de los vocablos jurídicos, medio de referencia que las normas guardan en relación con los hechos, la realidad y los comporta-

$11 \mathrm{Al}$ principio in dubio contra fiscum le son equiparables los alcances que tiene el principio in dubio pro reo en el ámbito penal. Dino Jarach, Curso superior de derecho tributario, (Buenos Aires: Cima, 1957), 246.

12 Desde tiempos de Modestino se afirmó que la ley tributaria debe interpretarse con ánimo favorable al contribuyente, debido al carácter servil y opresivo de los tributos. Miguel Mur Valdivia, «Elementos para la interpretación de las normas tributarias», Revista del Instituto Peruano de Derecho Tributario, ${ }^{\circ} 24$ (junio 1993): 56.

13 José Juan Ferreiro Lapatza, Curso de derecho financiero español (Madrid: Marcial Pons, 1992), 77.

14 Constituye un conjunto de reglas homogéneas que se concatenan en un grupo orgánico y singularizado que, a su vez, está unido a la totalidad del sistema jurídico. Héctor Villegas, Curso de finanzas, derecho financiero y tributario (Buenos Aires: De Palma, 1992), 144.

15 Alberto Tarsitano, «Teoría de la interpretación tributaria», en El tributo y su aplicación perspectivas para el siglo XXI, tomo 1, coords. César García Novoa y Catalina Hoyos Jiménez (Madrid: Marcial Pons, 2008), 853, http:/ /www.albertotarsitano.com/interpretacion/15teoriainterpretacion.pdf 
mientos tipificados en ella. Se recurre a la interpretación histórica y teleológica.

c) El pragmático, que se refiere a la manera en la cual los sujetos utilizan el lenguaje del derecho dentro de la comunidad donde viven. En este obran la interpretación sistemática, histórica y teleológica ${ }^{16}$.

Creemos que no existe un método de interpretación superior o prevalente, sino que deben combinarse armónicamente varios de ellos, y que el intérprete discrecionalmente elige, sin perder de vista la orientación de los principios y disposiciones constitucionales ${ }^{17}$.

\section{Criterios interpretativos}

El criterio interpretativo es un patrón de referencia o punto de partida que guía el trabajo interpretativo, no previsto en el primer párrafo de la Norma VIII del Título Preliminar del Código Tributario ${ }^{18}$, que, en la práctica, el intérprete escoge inconscientemente y de forma empírica, con criterio poco reflexivo, cuando más bien debe seleccionar dichos criterios reflexivamente y enunciarlos con claridad para sí mismo antes de proponer soluciones interpretativas propias en el derecho tributario ${ }^{19}$.

\subsection{Criterio normativo}

Al adoptar este criterio, el intérprete asume como punto de partida que la tarea de interpretación de una norma jurídica se efectúa a partir del derecho mismo, sin intervención de elementos extraños a lo técnicamente legal; extrae siempre sus contenidos interpretativos del mismo derecho y no recurre a elementos extraños ${ }^{20}$.

16 Carvalho, Curso de derecho tributario, 134-136.

17 Rosendo Huamaní, Código tributario comentado, vol. 1 (Lima: Jurista Editores, 2019), 271.

18 Francisco Ruiz de Castilla, Derecho tributario: temas básicos (Lima: Fondo Editorial PUCP, 2017), 163. https://repositorio.pucp.edu.pe/index/bitstream/handle/123456789/170670/11\%20 Derecho\%20tributario\%20con\%20sello.pdf?fbclid=IwAR2iaxm6skk2zUraENt_SmL6BvjPmSZVxqdJ9V0ENTzMZgxf8-B1kHG-QQ

19 Marcial Rubio Correa, Interpretación de las normas tributarias (Lima: ARA Editores, 2003), 71.

20 Rubio Correa, El sistema jurídico, 234. 
En el derecho tributario, siguiendo el criterio normativo, el intérprete usa como patrón de referencia el mandato de la norma jurídica tributaria legislada; se centra en la norma individualmente considerada y enriquecida en su relación con el resto del derecho. No admite, así, la presencia de otras entidades, como los principios, salvo para remediar la carencia de una previsión normativa expresa en una norma tributaria ${ }^{21}$.

\subsection{Criterio principista}

Con este criterio el intérprete asume como punto de partida que la tarea de interpretación consiste en adecuar el resultado, en la medida de lo posible, a ciertos valores que deben imperar en la aplicación del derecho. Este criterio, también denominado axiológico — por oposición al tecnicista—, sí hace intervenir elementos extraños a lo propiamente técnico-jurídico en la tarea de interpretación ${ }^{22}$.

Dichos elementos extraños son enunciados lógicos de dimensión axiológica, implícitos o explícitos, que, por su gran generalidad, ocupan una posición de preeminencia en los vastos cuadrantes del derecho. $Y$ es precisamente por esta razón que vincula, de modo inexorable, el entendimiento y la aplicación de las normas jurídicas que con él se conectan ${ }^{23}$.

Este criterio de referencia para interpretar la norma tributaria recurre a elementos extra técnico-jurídicos, como los principios vinculados al derecho que se incorporan para proceder a la interpretación de la norma tributaria ${ }^{24}$. Tales principios no se basan en la decisión particular de ningún tribunal u órgano legislativo, sino en un sentido de convivencia u oportunidad que, tanto

21 Rubio Correa, Interpretación de las normas tributarias, 72 y 73.

22 Rubio Correa, El sistema jurídico, 235.

23 Roque Antonio Carraza. Citado por: Carlos E. Peralta, «Tributación y derechos fundamentales, los principios constitucionales como límite al poder tributario: reflexiones a partir de los ordenamientos jurídicos de Brasil y Costa Rica», Revista de Ciencias Jurídicas, n. ${ }^{\circ} 138$ (setiembre-diciembre 2015): 105, https://revistas.ucr.ac.cr/index.php/juridicas/article/ view $/ 22824 / 23304$

24 Rubio Correa, Interpretación de las normas tributarias, 76 y 77. 
en el foro como en la sociedad, se desarrolla con el tiempo ${ }^{25}$ y confiere derechos y obligaciones ${ }^{26}$.

En el derecho tributario nos podemos referir a los «sobreprincipios que aparecen de la conjunción de principios» ${ }^{27}$, como son, entre otros, la seguridad jurídica, la certeza, la previsibilidad y la confianza legítima que se hallan en los principios de legalidad y reserva de ley, importantes para asegurar las obligaciones tributarias y el respeto a los derechos del contribuyente.

Los sobreprincipios de justicia y equidad surgen de la conjunción de los principios de capacidad contributiva, igualdad y no confiscatoriedad, pues todos los sujetos que poseen un determinado nivel de riqueza económica tienen que soportar un mismo nivel de carga tributaria, que no sustraiga toda la riqueza, sino solamente una parte.

El sobreprincipio de respeto a los derechos fundamentales que se manifiesta en los valores de la vida, la salud, la propiedad, la libertad, etc., busca ampliar la protección de estos derechos en el campo tributario, pues obliga a las autoridades a interpretar la norma tributaria oscura o contradictoria, susceptible de restringir los derechos del contribuyente, en el sentido de que brinde la mayor protección o exija la menor restricción del derecho ${ }^{28}$.

\subsection{Criterio de intereses}

Aquí son los intereses en juego los que dominan la interpretación de la norma, puesto que se constituyen como el punto de referencia ${ }^{29}$. El propio intérprete ha establecido previamente los objetivos por lograr mediante el derecho ${ }^{30}$. En el ámbito tributario, el interés de la administración tributaria es la recaudación fiscal, que se opone al interés del contribuyente de evitar el pago del

25 José Francisco Barth, «Principios y normas en la concepción del derecho de Dworkin», Revista de Ciencias Jurídicas, n. ${ }^{\circ} 108$ (setiembre-diciembre 2005): 185, https://revistas.ucr.ac.cr/index. php/juridicas/article/view/9716/9162

26 Barth, «Principios y normas en la concepción del derecho de Dworkin», 185.

27 Paulo de Barros Carvalho, «Principios y sobreprincipios en la interpretacion del Derecho», en Derecho Tributario: tópicos contemporáneos, eds. Jorge Bravo Cucci y Daniel Yacolca Estares (Lima: Grijley, 2011), 69.

28 Israel Santos, «La interpretacion de la norma tributaria», 88.

29 Francisco Ruiz de Castilla, Derecho tributario, 164.

30 Rubio Correa, El sistema jurídico, 235. 
tributo $^{31}$, lo cual es éticamente discutible, pues se instrumenta al derecho para intereses propios $^{32}$.

El criterio del interés reduce la dimensión de las normas a meros mandatos formales para la obtención de ingresos o en favor de intereses, ajenos a cualquier fundamentación o legitimación basadas en principios de plano constitucional y de raíz axiológica. Parcializa la visión llevándonos a conclusiones equivocadas al perderlos de vista ${ }^{33}$.

\section{Posición de criterio principista}

$\mathrm{Al}$ interpretar la norma tributaria, se debe adoptar un criterio principista como referencia o punto de partida, ya que esto permite introducir en lo técnicamente legal los valores que el derecho tributario contiene; se exige, así, al intérprete que se envuelva no solo con las normas tributarias y con el resto del derecho, sino también con los principios normativos que iluminan el conocimiento y la comprensión de la norma tributaria. Nos referimos, entre otros, a los principios de legalidad, igualdad, capacidad contributiva, no confiscatoriedad y respeto a los derechos fundamentales.

En el fondo, dichos principios son una exigencia de moralidad tributaria que se guía conforme a los valores de justicia, solidaridad, seguridad y garantía de la libertad de los individuos contra la arbitrariedad y el abuso del poder tanto del Estado como del contribuyente. Se vinculan así, de modo inexorable, el entendimiento y la aplicación de las normas jurídicas que con él se conectan ${ }^{34}$.

Así, los principios son núcleos significativos axiológicos que expresan una preferencia general y abstracta por ciertos contenidos de expectativa que influyen en la interpretación de la norma ${ }^{35}$ que cada intérprete elige y ordena.

Como dice Calvo Ortega, ««el principalismo es una herramienta suficiente para resolver gran parte de las dudas que puedan presentarse en la aplicación de las normas tributarias ${ }^{36}$, ya que el derecho no solo está formado por

31 Rubio Correa, Interpretación de las normas tributarias, 81.

32 Rubio Correa, Interpretación de las normas tributarias, 81.

33 Tarsitano, «Interpretacion de la ley tributaria», 420.

34 Peralta, «Tributación y derechos fundamentales», 105-107.

35 Carvalho, «Principios y sobreprincipios en la interpretacion del Derecho», 69.

36 Rafael Calvo. Citado por Cazorla, Derecho financiero y tributario, 148. 
normas jurídicas, sino también por principios jurídicos que son observados no porque aseguren una situación económica, política o social deseable, sino porque constituyen un requerimiento de justicia o equidad, o bien alguna otra consideración moral ${ }^{37}$.

\section{Métodos de interpretación}

Una vez elegido un criterio de referencia, el intérprete procede a utilizar los métodos de interpretación admitidos por el derecho; como indica Rubio ${ }^{38}$, la relación entre ambos debe ser dialéctica para comparar los resultados de interpretación obtenidos y el criterio de referencia adoptado.

\subsection{Método literal}

La interpretación de la norma tributaria conlleva atribuirles un significado a las palabras, por medio de las reglas semánticas y del orden sintáctico establecido $^{39}$; es decir, debe considerarse el significado literal o propio de las palabras que la integran según su significado jurídico, especifico (técnico), o común, así como su construcción gramatical, sin restringirlo o extenderlo ${ }^{40}$.

En cuanto al significado jurídico del término, este puede ser aquel definido por la norma tributaria. En caso de que esta no lo haga expresamente, se habrá de recurrir al significado que brinda el derecho. Si este no existiese, se buscará su significado técnico o específico en las ciencias no jurídicas; y, finalmente, el usual, que es el que proviene de la realidad social ${ }^{41}$.

Este orden de preeminencia para asignar un sentido a los términos puede basarse en la Norma IX del Título Preliminar del Código Tributario ${ }^{42}$. Esta

37 Ronald Dworkin, «The model of rules», University of Chicago Law Review 35, n. ${ }^{\circ} 1$ (1967): 23, https: / / chicagounbound.uchicago.edu/cgi/viewcontent.cgi?article $=3553 \&$ context=uclrev

38 Rubio Correa, Interpretación de las normas tributarias, 133.

39 Tarsitano, «Interpretacion de la ley tributaria», 429.

40 Rubio Correa, El sistema jurídico. Introducción al derecho, p. 220.

41 Cazorla, Derecho financiero y tributario, 149.

42 Norma IX del Título Preliminar del Código Tributario: «En lo no previsto por este Código o en otras normas tributarias podrán aplicarse normas distintas a las tributarias siempre que no se les opongan ni las desnaturalicen. Supletoriamente se aplicarán los Principios del Derecho Tributario, o en su defecto, los Principios del Derecho Administrativo y los Principios Generales del Derecho». 
señala, fundamentalmente, que en lo previsto en la norma tributaria se puede recurrir a otras normas distintas, siempre que estas no se opongan a ella o la desnaturalicen.

Como ejemplos de atribución de significado a las palabras, podemos citar:

- La resolución del Tribunal Fiscal 11831-7-2008, en lo que se refiere a la expresión mutuo disenso, no prevista en la norma tributaria. En este caso, buscó su significado en el artículo 1313 del Código Civil.

- Las resoluciones del Tribunal Fiscal 8873-3-2007 y 5239-3-2002, que a fin de decidir la inscripción en el Registro de Entidades Exoneradas del Impuesto a la Renta de una asociación sin fines de lucro cuya finalidad era la asistencia social, recurrió a la definición del término asistencia dada por la Enciclopedia jurídica OMEBA ${ }^{43}$. Concluyó, así, que dicha actividad debe dirigirse solo a quienes no cuentan con los medios económicos suficientes para solventarse.

- El Tribunal Fiscal, para la resolución 2213-1-2017, necesitaba determinar el alcance de la expresión maquinaria y equipo, pues la Ley del Impuesto a la Renta no tiene una definición propia. Con esta finalidad, recurrió al Diccionario de la lengua española, al Diccionario de contabilidad y finanzas y a la Norma Internacional de Contabilidad NIC 16.

En cuanto a la construcción gramatical, el Tribunal Fiscal, en su resolución 223-4-2003, concerniente a la redacción del artículo 56 del Código Tributario ${ }^{44}$, indicó que la conjunción disyuntiva o establece la existencia de dos supuestos distintos e independientes en los cuales la Administración Tributaria se encuentra facultada a trabar medidas cautelares previas:

i) Cuando sea indispensable a causa del comportamiento del deudor tributario, supuesto que se verifica en el momento en que se presenten cualquiera de las situaciones reguladas en este artículo.

43 La Enciclopedia jurídica OMEBA, en su definición de asistencia, recoge la acepción común 'prestar ayuda o socorro', a la vez que indica también un sentido restringido: 'atención profesional sea médica, jurídica o religiosa, etc. a toda persona o grupo de ellas en trance de necesitarla'.

44 Artículo 56, sustituido por el artículo 24 del Decreto Legislativo 953 del 5 de febrero de 2004: «Excepcionalmente, cuando por el comportamiento del deudor tributario sea indispensable o, existan razones que permitan presumir que la cobranza podría devenir en infructuosa, antes de iniciado el Procedimiento de Cobranza Coactiva, la Administración a fin de asegurar el pago de la deuda tributaria, y de acuerdo a las normas del presente Código Tributario, podrá trabar medidas cautelares por la suma que baste para satisfacer dicha deuda, inclusive cuando ésta no sea exigible coactivamente...». 
ii) Cuando existan razones que permitan presumir que la cobranza podría devenir en infructuosa.

La sentencia de casación 16533-2013 Lima concluye — también desde una interpretación de la construcción gramatical - que el inciso a) del artículo 93 de la Ley del Impuesto a la Renta, TUO aprobado mediante Decreto Supremo 054.99.EF, deja abierta la posibilidad de que al momento de determinar la deuda tributaria se emplee como coeficiente la evaluación del propio negocio y no excluyentemente a empresas similares, ya que la norma señala: «Para los efectos de determinación sobre base presunta la Superintendencia Nacional de Administración Tributaria podrá utilizar; a) Coeficientes.- A tal fin servirán especialmente como elementos determinantes: ...el rendimiento normal del negocio o explotación de empresas similares;...».

\subsection{Interpretación lógica o ratio legis}

La interpretación de la norma tributaria debe ser determinada sobre la base del análisis del texto de la norma para hallar la razón de ser de esta, su sentido y alcance sin limitarse a la gramática ${ }^{45}$ o a la redacción del texto, sino como explicación de por qué y para qué fue dictada, con la finalidad de desentrañar lo esencial de su contenido.

El Tribunal Fiscal, en la resolución 12379-5-2015, interpreta lógicamente el numeral 1.3), inciso b) del artículo 19 del Reglamento de la Ley del Impuesto a la Renta, que se refiere a las reglas de valor de mercado de las remuneraciones: «En caso de no existir los referentes anteriormente señalados, será el doble de la remuneración del trabajador mejor remunerado entre aquellos que se ubiquen dentro del grado, categoría o nivel jerárquico inmediato inferior, dentro de la estructura organizacional de la empresa». Concluye que el trabajador referente es el que está mejor remunerado dentro de la estructura organizacional de la empresa, entre aquellos que se ubiquen dentro del grado, categoría o nivel jerárquico inferior. Esto no implica necesariamente que se trate de aquel que dependa funcionalmente del accionista o socio que está siendo analizado tributariamente; es decir, no se aplica el criterio funcional vertical, sino el de la mejor remuneración, lo cual tiene correlato con el valor de mercado.

45 Rubio Correa, El sistema jurídico, 220. 
La sentencia de casación 9337-2015 Lima hace una interpretación lógica del segundo párrafo del artículo $136^{46}$ y del literal a) del numeral 3 del artículo $119^{47}$ del Código Tributario. Según su conclusión, procede admitir a trámite la reclamación contra una orden de pago sin necesidad de pagar antes la deuda; basta, para ello, la sola invocación de la existencia de "circunstancias que evidencien la improcedencia de la cobranza», ya que esto no puede resolverse en la etapa de calificación del recurso de reclamación (verificación de los requisitos formales para la admisión del recurso) - como pretenden la Administración Fiscal y el Tribunal Fiscal al amparo de las referidas normas-, sino en la posterior etapa de evaluación, en la que se revisan los argumentos y medios probatorios ofrecidos por el contribuyente. En otras palabras, verificar si la cobranza resulta improcedente es algo que solo puede determinarse en la etapa de evaluación.

También la sentencia de casación 4796-2018 Lima recurre a una interpretación lógica para esclarecer el sentido del penúltimo párrafo del artículo 3 de la Ley del Impuesto a la Renta: «En general, constituye renta gravada de las empresas, cualquier ganancia o ingreso derivado de operaciones con terceros» (teoría del flujo de la riqueza). Indica que, si bien califican las trasferencias de bienes a título gratuito en favor de una empresa como ingreso afecto para esta última, no se hallan dentro del alcance de la norma aquellos bienes recibidos gratuitamente como parte del ciclo de comercialización que terminan siendo transferidos gratuitamente a clientes finales.

\subsection{Método sistemático}

Explica que la norma no se interpreta de forma aislada, sino más bien armónica, atendiendo al modo en que se vinculan las diversas disposiciones de un mismo cuerpo normativo, considerando las distintas disposiciones jurídicas y los principios jurídicos como partes de un todo ${ }^{48}$. Para salvar las

46 «Artículo $136^{\circ}$.- REQUISITO DEL PAGO PREVIO PARA INTERPONER RECLAMACIONES

(...) Para interponer reclamación contra la Orden de Pago es requisito acreditar el pago previo de la totalidad de la deuda tributaria actualizada hasta la fecha en que realice el pago, excepto en el caso establecido en el numeral 3 del inciso a) del Artículo $119^{\circ}{ }$.

47 Excepcionalmente, tratándose de órdenes de pago, y cuando medien otras circunstancias que evidencien que la cobranza podría ser improcedente, y siempre que la reclamación se hubiera interpuesto dentro del plazo de veinte días hábiles de notificada la orden de pago.

48 Santos, «La interpretacion de la norma tributaria.», 73. 
contradicciones entre normas jurídicas, en este método se aplican, entre otros principios, los de la ley posterior prevalece sobre la anterior, la ley especial predomina sobre la general, los tratados prevalecen sobre la ley.

El método sistemático de interpretación tiene dos modalidades: por comparación de normas y por ubicación de la norma.

\subsubsection{La interpretación sistemática por comparación de normas}

Este método consiste en averiguar el significado del mandato de una norma cuando aquel no se encuentra claramente expresado. Para esclarecerlo, se la compara con alguna otra norma que la enriquece por compartir principios y conceptos equivalentes, pero expresados con claridad ${ }^{49}$. Así, se precisa el contenido de la norma oscura con la ratio legis común de otra norma ${ }^{50}$.

El método sistemático por comparación de normas utilizado en el derecho tributario puede recurrir al orden de preeminencia de la Norma IX del Título Preliminar del Código Tributario. Esta indica que, en aquellas situaciones que no se encuentren previstas por dicho cuerpo normativo, podrán aplicarse normas distintas de las tributarias, siempre y cuando no se les opongan ni la desnaturalicen.

La resolución del Tribunal Fiscal 21854-1-2011, mediante una interpretación sistemática, precisó que para la prestación del servicio exonerado de IGV de transporte de carga, tracción de contenedor y practicaje, según el numeral 3 del Apéndice II de la Ley de IGV, es posible valerse de terceros. Recurrió, para el efecto, al artículo 1766 del Código Civil. Este señala que, para la prestación de servicios, «el locador puede valerse, bajo su propia dirección y responsabilidad de auxiliares y sustitutos, si la colaboración de otros está permitida por el contrato o por los usos y no es incompatible con la naturaleza de la prestación».

La sentencia de casación 14785-2014 Lima, efectúa una interpretación sistemática de normas tributarias y de otras que no tienen contenido tributario: los artículos 7, 8 y 9 del Texto Único Ordenado del Código Tributario, aprobado por Decreto Supremo 135-99-EF; el artículo 7, apartado 7.4 del Decreto Ley 22774, Bases Generales para Contratos Petroleros en Operaciones de Ex-

49 Rubio Correa, El sistema jurídico, 220.

50 Rubio Correa, Manual de razonamiento jurídico (Lima: Fondo Editorial de la PUCP, 2017), 97. 
ploración; y el artículo 69 del Texto Único Ordenado de la Ley del Impuesto General a las Ventas e Impuesto Selectivo al Consumo, aprobado por Decreto Supremo 055-99-EF. Concluye que el impuesto general a las ventas pagado y deducido como gasto para la determinación del impuesto a la renta por parte de Petroperú no puede ser legalmente utilizado por la empresa Savia como crédito fiscal.

En la RTF 05847-5-2002 para establecer los alcances de la institución de la nulidad parcial de una acto administrativo tributario no previsto en el Código Tributario amparándose en la Norma IX del Título Preliminar del Código Tributario, el Tribunal Fiscal aplicó supletoriamente el artículo 224 del Código Civil, el numeral 13.2 de la Ley del Procedimiento Administrativo General, y los principios de eficacia del acto administrativo, conservación del acto, simplicidad, celeridad y economía. Concluyó, de esta manera, que la declaratoria de nulidad parcial requiere en forma conjunta tres condiciones: i) que el contenido del acto sea divisible en unidades independientes, ii) que el vicio solo afecte una parte del acto, y iii) que la parte no afectada por el vicio de nulidad se conserve firme ${ }^{51}$.

También el Tribunal Fiscal recurrió al método sistemático por comparación (más sentencia del Tribunal Constitucional) para afirmar los requisitos mínimos que la Administración Tributaria debe considerar en caso de que disponga ordenar una medida cautelar previa. Tales requisitos no se hallaban previstos en el Código Tributario, por lo que el tribunal se amparó implícitamente en la Norma IX del Título Preliminar del Código Tributario para aplicar supletoriamente la STC Exp. 0015-2005-PI/TC, emitida el 5 de enero de 2006 y los numerales 1) y 4) del artículo 146 de la Ley del Procedimiento Administrativo General. Resolvió, así, que la Administración Fiscal, para adoptar una medida cautelar, debe acreditar como mínimo lo siguiente: i) la verosimilitud de la deuda tributaria, debiendo acompañar los medios probatorios que correspondan; y ii) el peligro irreparable que conllevaría esperar el fallo definitivo sobre la deuda tributaria.

51 Actualmente está prevista la nulidad parcial en el artículo 109 del Código Tributario, modificado por el Decreto Legislativo 1263, vigente desde el 12 de diciembre de 2016. 


\subsubsection{Método sistemático por ubicación de la norma}

Según este método la interpretación de la norma debe hacerse recurriendo al «conjunto, subconjunto, grupo normativo, etcétera, en el cual se halla incorporada que por compartir reglas y principios permiten que la estructura normativa en la que se ubica esclarezca y enriquezca su sentido» ${ }^{52}$ su significado y regule específicamente un determinado campo de la realidad excluyendo a las demás ${ }^{53}$.

En la RTF 5717-1-2019 se hace una interpretación sistemática del inciso a) del artículo 18 de la Ley del Impuesto General a las Ventas y el artículo 37 de la Ley del Impuesto a la Renta para esclarecer que la citada norma concerniente al IGV sí necesita tener en consideración los límites previstos en la Ley del Impuesto a la Renta a fin de gozar del crédito fiscal, puesto que el requisito sustancial para la utilización de este es que sean permitidos como gasto o costo; si el exceso del límite fijado en la Ley del Impuesto a la Renta no es gasto deducible, tampoco cumple, por lo tanto, con el requisito para el uso del crédito fiscal.

La RTF 10167-2-2007 interpreta sistemáticamente el artículo 57, inciso a) de la Ley del Impuesto a la Renta, así como los artículos 31 y 35, inciso d) del Reglamento de la Ley del Impuesto a la Renta. Indica que el artículo 57, inciso a) de la Ley del Impuesto a la Renta y el artículo 31 del reglamento de la Ley del Impuesto a la Renta se refieren a gastos de ejercicios anteriores que pueden ser deducidos en un ejercicio posterior solo en caso de que los gastos sean provisionados previamente a su pago en el ejercicio en que este se efectúe. Esclarece que se trata de una situación distinta de la que contempla el artículo 35, inciso d) del Reglamento de la Ley del Impuesto a la Renta, referido a la deducción como gasto de las pérdidas por faltantes de inventario, siempre que los inventarios físicos y su valorización hayan sido aprobados por los responsables de su ejecución, aun cuando - como ocurra en el presente casoestas se deduzcan en el ejercicio siguiente; no requiere para su deducción la realización de un pago.

52 Rubio Correa, El sistema jurídico, 245.

53 Rubio Correa, Marcial, Interpretación de las normas tributarias, 148. 


\subsection{Interpretación histórica}

Consiste en desentrañar el sentido de una norma utilizando las exposiciones de motivos del proyecto legislativo, los fundamentos puestos en la parte considerativa de la norma, las normas en las cuales se inspiró el legislador y las normas derogadas, el contraste entre la norma por interpretar y las precedentes o antecedentes que fueron modificadas o suprimidas, así como la ocassio legis: cuál era la situación concreta que originó en su momento la creación de la norma ${ }^{54}$.

La RTF 2398-11-2021 hace una interpretación histórica recurriendo a la exposición de motivos, contrasta la norma por interpretar con aquellas que la precedieron, y aplica la ocassio legis para interpretar el sentido del último párrafo del artículo $14^{55}{ }^{56}$ en cuanto al tratamiento del asociado en los contratos de asociación en participación (AEP).

Primero hace una referencia a una ley antigua, al último párrafo de los artículos 14 y 65 de la Ley del Impuesto a la Renta —aprobada mediante Decreto Legislativo 774 y modificada por Decreto Legislativo 799, y que estuvo vigente hasta el ejercicio 1998-, el cual trataba a las asociaciones en participación (AEP) como contribuyentes del impuesto a la renta, estando obligadas a determinar sus obligaciones tributarias, llevar contabilidad de forma independiente de la de sus partes, y a atribuir las rentas a las personas jurídicas o naturales que se constituyan como partes contratantes (trasparencia fiscal), las cuales las incorporaban a sus propios resultados, entendiéndose que cada parte llevaba a cabo una actividad de tipo empresarial.

El intérprete contrasta dicha situación con el cambio que introdujo la Ley 27034, vigente desde el 1 de enero de 1999. Esta norma, al modificar la Ley del Impuesto a la Renta, excluyó a las AEP como sujetos del impuesto y eliminó el régimen de «transparencia fiscal» aplicable a ellas. Así, de conformidad con la

54 Rubio Correa, Manual de razonamiento jurídico,112-117; Rubio Correa, Interpretación de las normas tributarias, 152; Rubio Correa, El sistema jurídico, 248.

55 «En el caso de las sociedades irregulares previstas en el Artículo $423^{\circ}$ de la Ley General de Sociedades, excepto aquellas que adquieren tal condición por incurrir en las causales previstas en los numerales 5 y 6 de dicho artículo; comunidad de bienes; joint ventures, consorcios y demás contratos de colaboración empresarial que no lleven contabilidad independiente, las rentas serán atribuidas a las personas naturales o jurídicas que las integran o que sean parte contratante».

56 Sustituido por el artículo 3 de la Ley 27034, publicada el 30 de diciembre de 1998. 
nueva regulación, el asociante declaraba los ingresos generados del negocio y pagaba lo correspondiente a renta de tercera categoría del impuesto a la renta, y la actividad del asociado era la de un socio.

También recurrió el intérprete a la exposición de motivos de la Ley 27034, la cual señala que «carece de sustento jurídico atribuir rentas al asociado»; con ello se hace referencia a que el asociado no es el que desarrolla la actividad empresarial, por lo que no corresponde atribuirle rentas de tercera categoría.

Posteriormente, con base en la ocassio legis, el intérprete entendió que la Resolución de Superintendencia 042-2000/Sunat, publicada el 21 de marzo de 2000, había sido un régimen transitorio aplicable únicamente al ejercicio 1999 para el caso de los asociantes de AEP existentes al 1 de enero de 1999 que llevaran contabilidad independiente; esta consistía, según el artículo 6 de la mencionada resolución, en que el asociado declarará la participación como renta de tercera categoría del impuesto a la renta y el asociante lo deducirá como gasto o costo.

Con base en la interpretación de los antecedentes normativos, el intérprete concluye que el tratamiento tributario del último párrafo del artículo 14 de la Ley del Impuesto a la Renta, aplicable para las AEP constituidas con posterioridad al 1 de enero de 1999, es que «la participación del asociado, para los efectos del Impuesto a la Renta, califica como dividendo u otra forma de distribución de utilidades» ${ }^{57}$.

\section{Apotegmas de interpretación}

Son proposiciones o argumentos afirmativos claros tomados como correctos y válidos, salvo que la legislación vigente haga una excepción ${ }^{58}$. Expresan una sabiduría específica de antigua existencia en el derecho y ayudan a resolver puntos concretos para los métodos de interpretación ${ }^{59}$.

El alcance y significación de estas proposiciones se aprecia en la actualidad.

57 Si el asociado recibe el dividendo como persona jurídica domiciliada en el país, dicho ingreso no está gravado con el impuesto a la renta. Si se trata de una persona natural o de un ente distinto de una persona jurídica domiciliada en el país, el ingreso estará gravado con el impuesto a la renta de segunda categoría.

58 Rubio Correa, Manual de razonamiento jurídico, 162.

59 Rubio Correa, El sistema jurídico, 254. 


\subsection{No hay que distinguir donde la ley no distingue}

La resolución del Tribunal Fiscal 6075-9-2018, empleando el método de interpretación literal, se apoyó en el apotegma «No hay que distinguir donde la ley no distingue», pues indicó que la provisión de cobranza dudosa regulada por el artículo 37, inciso d) de la Ley de Impuesto a la Renta no distingue que el deudor deba ser necesariamente cliente del contribuyente, por lo que las deudas del proveedor pueden ser también materia de provisión de cobranza dudosa.

\subsection{El que puede lo más debe poder lo menos}

El Tribunal Fiscal en la Resolución 2097-2-2007, desde una interpretación lógica sostenida en el apotegma «El que puede lo más debe poder lo menos», concluyó que cabe la adopción de medidas cautelares previas incluso cuando hay recurso impugnatorio contra el acto administrativo. Explica que, si se permite trabar las citadas medidas cautelares antes de la emisión de valores, conforme al artículo 58 del Código Tributario ${ }^{60}$, «excepcionalmente, cuando el proceso de fiscalización o verificación amerite la adopción de medidas cautelares, la Administración Tributaria, bajo responsabilidad, trabará las necesarias»; sería incoherente no permitirlas una vez emitidas en la etapa de reclamación, durante la cual sería posible determinar causales para su adopción.

\subsection{A lo imposible nadie está obligado}

En la Resolución 222-1-2020, el Tribunal Fiscal aplicó una interpretación lógica vinculada al apotegma «A lo imposible nadie está obligado» con respecto a lo siguiente: la «cancelación del tributo» a la que se refiere el inciso b.1 del literal b) del numeral 1 del artículo 13-A del Reglamento de Gradualidad para acceder a la rebaja del 95 \% de la sanción de multa, únicamente es exigible cuando, producto de la subsanación a través de la presentación de una declaración

60 Artículo 58 del Código Tributario: «Excepcionalmente, cuando el proceso de fiscalización o verificación amerite la adopción de medidas cautelares, la Administración Tributaria, bajo responsabilidad, trabará las necesarias para garantizar la deuda tributaria, aun cuando no hubiese emitido la Resolución de Determinación, Resolución de Multa u Orden de Pago de la deuda tributaria». 
rectificatoria, exista un tributo por regularizar, pero no al haber saldos a favor o pérdidas en dichas declaraciones.

El intérprete concluye que si la recurrente cumplió con la subsanación oportuna de la infracción (mediante la presentación de la declaración rectificatoria), el requisito de la «cancelación del tributo» no resulta exigible por haber determinado saldos a favor o pérdidas. En consecuencia, se acoge correctamente a la gradualidad del $95 \%$.

\subsection{Solo le está permitido al Estado aquello que expresamente le ha sido conferido.}

En la resolución del Tribunal Fiscal 09-1-1994 se hizo una interpretación lógica restrictiva del numeral 1 del artículo 62 del Código Tributario, Decreto Legislativo $773^{61}$, apoyada en el apotegma «Solo le está permitido al Estado aquello que expresamente le ha sido conferido», que establece la facultad de la Administración de requerir a los contribuyentes la presentación de sus libros y demás documentos contables.

En este caso, el Tribunal Fiscal estableció que la razón de la citada norma era facultar a la Administración a requerir al contribuyente la exhibición de su documentación con el objeto de verificar el cumplimento de sus obligaciones tributarias. Esta pretensión queda satisfecha con la exhibición que se haga de los documentos correspondientes en el domicilio fiscal del contribuyente, ya que exigir el traslado de la documentación contable a las oficinas de la Administración constituiría un exceso de esta facultad.

Otro caso fue la resolución del Tribunal Fiscal 8148-4-2019. En ella se señaló que la infracción tipificada en el numeral 5 del artículo 177 del Código Tributario ${ }^{62}$, relacionada con la no exhibición de documentos e información solicitados por la Administración sobre sus actividades o la de terceros, solo se configura cuando un contribuyente no presenta información que se encuentra obligado a elaborar. No calificando como tal la documentación que

61 Actualmente el Código Tributario ha previsto que la Administración Tributaria está facultada para requerir la exhibición de los libros y demás documentación contable en las oficinas de la administración.

62 Infracción numeral 5 del artículo 177 del Código Tributario: «No proporcionar la información o documentos que sean requeridos por la Administración sobre sus actividades o las de terceros con los que guarde relación o proporcionarla sin observar la forma, plazos y condiciones que establezca la Administración Tributaria». 
los terceros proveedores generan y mantienen en su poder, ni aquella que el contribuyente no haya tenido la obligación de solicitar (por ejemplo, detalle de costos, margen de ganancia, etc., de su proveedor).

\subsection{Lo que no está prohibido está permitido}

En la sentencia de casación 3727-2016 Lima, la Corte Suprema resuelve que del artículo 87 de la Ley del Impuesto a la Renta y del artículo 55 del Reglamento de la Ley del Impuesto a la Renta no se desprende explícitamente prohibición alguna que impida al contribuyente utilizar el saldo a favor originado por el impuesto a la renta para compensar el pago de otro impuesto - como la deuda del ITAN-, considerando que en el caso de los administrados, conforme con el principio de legalidad, lo que no está prohibido está permitido. En ese sentido, procede la solicitud de compensación.

\subsection{En todo derecho, lo específico deroga a lo genérico, y prevalece siempre lo que se refiere a lo específico}

La Corte Suprema, mediante sentencia de casación 3706-2006 Lima, interpreta que el tratamiento tributario de los activos intangibles de duración limitada a los que se refiere el literal g) del artículo 44 de la Ley del Impuesto a la Renta solo es aplicable a aquellos activos que tienen naturaleza similar a los que menciona el reglamento (patentes, modelos de utilidad, derechos de autor, derechos de llave, diseños o modelos, planos, procesos o fórmulas secretas, así como programas de instrucciones para computadoras). Es decir, no resulta aplicable a las concesiones mineras, a las cuales, por un criterio de especialidad, se les aplicará lo dispuesto en el artículo 74 de la Ley General de Minería.

\section{La analogía y la interpretación excesiva de la norma tributaria}

El tercer párrafo de la Norma VIII del Título Preliminar señala que en vía de interpretación no podrán crearse tributos, establecerse sanciones, exoneraciones o aplicar las normas tributarias a personas o a supuestos distintos de los señalados en la ley. 
En la práctica hay que admitir que habrá casos en los que es posible distinguir entre aplicación analógica e interpretación extensiva, mientras que en otras, $\mathrm{no}^{63}$.

\subsection{La analogía}

El tercer párrafo de la citada norma del Título Preliminar prohíbe la analogía. Esta consiste en aplicar una norma que regula hechos distintos, aunque semejantes en esencia, a un hecho no contemplado expresamente ${ }^{64}$. En otras palabras, es un proceso de integración del derecho que se lleva a cabo al aplicar una norma a un supuesto no contemplado en ella, pero que se lleva a cabo porque existe identidad de razón o afinidad entre ambos supuestos.

En la analogía existe un vacío normativo que lleva a buscar una norma que comparta una afinidad o semejanza con el supuesto no contemplado.

En el campo tributario, la prohibición de utilizar la analogía no solo existe para impedir la integración de aquellos aspectos esenciales del tributo que signifiquen la creación de hechos novedosos generadores de la obligación tributaria, bases para su cálculo, alícuotas, sujetos de la obligación tributaria, sino también para sanciones o exoneraciones, todas las cuales pueden ser reguladas únicamente por ley o decreto legislativo. Esta prohibición de analogía se extiende también a los supuestos señalados en la Norma IV del Título Preliminar del Código Tributario ${ }^{65}$.

Esto es así, ya que los principios de legalidad tributaria y de seguridad jurídica, así como las disposiciones legales que establecen fórmulas dirigidas a condicionar la aplicación e interpretación de las normas tributarias, deben

63 Tarsitano, «Interpretacion de la ley tributaria», 429.

64 Rubio Correa, El sistema jurídico, 264.

65 «Norma IV: Principio de legalidad - Reserva de la ley.

Sólo por Ley o por Decreto Legislativo, en caso de delegación, se puede:

a) Crear, modificar y suprimir tributos; señalar el hecho generador de la obligación tributaria, la base para su cálculo y la alícuota; el acreedor tributario; el deudor tributario y el agente de retención o percepción, sin perjuicio de lo establecido en el Artículo $10^{\circ}$;

b) Conceder exoneraciones y otros beneficios tributarios;

c) Normar los procedimientos jurisdiccionales, así como los administrativos en cuanto a derechos o garantías del deudor tributario;

d) Definir las infracciones y establecer sanciones;

e) Establecer privilegios, preferencias y garantías para la deuda tributaria; y,

f) Normar formas de extinción de la obligación tributaria distintas a las establecidas en este Código». 
entenderse solamente en el sentido de impedir aplicaciones analógicas en relación con los elementos esenciales de los tributos ${ }^{66}$.

Sin embargo, la analogía es admitida con referencia a otros elementos no esenciales para la definición de la materia imponible, como los componentes de naturaleza lateral que sirven para determinar los conceptos accesorios ${ }^{67}$, así como en aquellas partes del ordenamiento tributario que no aparezcan expresamente reservadas para la ley ${ }^{68}$.

La Resolución del Tribunal Fiscal 7363, de fecha 24 de julio de 1972, estableció que es procedente el uso de la analogía para suplir la ausencia de regulación de aspectos sustantivos y formales de la norma tributaria, siempre que con ello no se viole el principio de legalidad.

Así, la Resolución del Tribunal Fiscal 2280-4-1996 aplicó la analogía para exigir la denuncia policial en caso de extravío de documentos contables, ya que el Reglamento de Comprobantes de Pago vigente a partir del 22 de mayo de 1995 no exigía expresamente la sustentación del robo o extravío de comprobantes de pago con la denuncia policial; sin embargo, esta obligación, según el Tribunal Fiscal, se imponía en razón de las disposiciones penales vigentes para casos de desaparición de documentos (situación análoga).

\subsection{Interpretación excesiva de las normas tributarias}

La interpretación excesiva de las normas tributarias está prohibida por el tercer párrafo de la Norma VIII del Título Preliminar porque fuerza los términos del sentido de la ley al extenderlos más allá de sus términos estrictos y de su ámbito, pues lleva a crear hechos imponibles, infracciones, exoneraciones o supuestos novedosos o contrarios a la ley no contemplados ni incluidos en ella.

En la interpretación extensiva se resuelve el vacío normativo desde la misma norma para regular el supuesto no previsto.

En el caso de la resolución del Tribunal Fiscal 16563-10-2012, la recurrente presentó una resolución que acreditaba su inscripción en el Libro de Clubes Deportivos del Registro Deportivo Regional del IPDT. El Tribunal Fiscal con-

66 Tesis 2a/J. 26/2006, Semanario Judicial de la Federación y su Gaceta, Novena Época, t. 23, marzo de 2006, p. 270. Citado por Santos, «La interpretacion de la norma tributaria», 84.

67 Fernando Rivera Postigo, Derecho tributario sustantivo (Lima: A\&B Servicio Gráfico, 1988), 79, 83.

68 Cazorla, Derecho financiero y tributario, 150. 
cluyó que no le correspondía la inafectación porque no contaba con la Resolución Suprema que la autorizaba ni con la calificación del IPD, requisitos contemplados en la Ley del Impuesto General a las Ventas, ya que aseverar lo contrario implicaría extender la aplicación de la norma a un supuesto distinto al señalado en la ley.

También en la resolución del Tribunal Fiscal 2418-11- 2019 se señala que no resultan admisibles como medio probatorio a ser actuados en sede administrativa las declaraciones juradas con firmas legalizadas ante notario público presentadas como prueba testimonial, pues solo se consideran admisibles las manifestaciones obtenidas por la Administración según el artículo 125 del Código Tributario. Interpretar lo contrario llevaría a extender las normas tributarias a supuestos distintos de los que se señala en la ley.

\subsection{Interpretación de las desgravaciones tributarias}

El derecho tributario no solo tiene finalidades recaudatorias, sino también extrafiscales. Por ello, el Estado, en ejercicio de su poder tributario, puede desgravar tributariamente ciertas actividades o contribuyentes utilizando diversas especies: inmunidad, inafectación, exoneración, beneficio e incentivo tributario, cuyo fin es la inexistencia, eliminación o reducción de la carga tributaria $^{69}$.

Estas especies de desgravación tributaria, en virtud del tercer párrafo de la Norma VIII del Título Preliminar, tienen la limitación de que «en vía de interpretación no podrá crearse... exoneraciones o aplicar las normas tributarias a personas o supuestos distintos a los señalados en la ley». Es decir, deben ser interpretadas de forma estricta o restrictiva, primando en la práctica la interpretación restrictiva.

\subsubsection{La interpretación declarativa o estricta}

Significa que el intérprete debe establecer el alcance de la norma apegándose al sentido propio o literal de las palabras empleadas por el legislador, sin restringirlo y tampoco sin extenderlo. Se respeta la letra de la ley «allí donde la

69 Francisco J. Ruiz de Castilla Ponce de León, «Inmunidad, inafectación, exoneración, beneficios e incentivos tributarios», Foro Jurídico, n. ${ }^{\circ} 12$ (marzo 2013): 137, https:/ / revistas.pucp.edu.pe/ index.php/forojuridico/article/view/13808/14432 
ley quiso, lo dijo; y lo que no dijo, es porque no quiso decirlo» (ubi lex voluit, dixit; ubi noluit, tacuit) $)^{70}$.

Así, en la resolución del Tribunal Fiscal 774-3-98, con respecto al beneficio de un fraccionamiento especial de deuda tributaria, se afirma que «al tratarse de una norma que regula un beneficio o sea una excepción al régimen general, debe ser interpretada en forma estricta y teniendo en cuenta el principio de legalidad que informa al Derecho Tributario».

\subsubsection{La interpretación restrictiva o restringida}

Implica que el intérprete atribuya a las palabras de la norma un alcance más reducido que el que aparentemente tiene. Se restringe el significado de las palabras para minimizar el efecto y alcance de la norma de tal manera que sea menor que lo que dice el texto de la ley (minus voluit quam dixit) ${ }^{71}$.

La resolución del Tribunal Fiscal 15907-7-2011 efectúa una interpretación restringida de la inafectación del impuesto predial de los predios de universidades, institutos superiores y demás centros educativos que se destinen a los fines propios de la actividad educativa; así, para considerarlos dentro del alcance de la inafectación, se restringe el significado de las palabras «el estar destinados a la actividad educativa» a estar siendo usados para actividades educativas o que estas se estén llevando a cabo.

El Poder Judicial ha seguido una perspectiva similar, siendo que en la Sentencia de Casación 106-2009-Lima se afirma que:

... [los alcances de la norma analizada] deben ser determinados teniendo en cuenta lo establecido en el artículo VIII del Título Preliminar del Código Tributario, por lo que la interpretación que se argumenta [que] se le debe dar a la norma señalada en el considerando precedente debe ser de carácter restrictivo; es decir, que no se pueden hacer interpretaciones extensivas para incorporar otras actividades y obtener una exoneración tributaria en general, cuando alguna de ellas por el principio de exclusividad, es gravada.

En conclusión, la interpretación de la norma tributaria no se limita solo a descubrir el significado o lo que quiere decir el texto oscuro de la norma, sino

70 Santos Flores, «La interpretacion de la norma tributaria», 76.

71 Santos Flores, «La interpretacion de la norma tributaria». 
también a recrear de nuevo su significado o el sentido que se hallaba oculto en el texto al aplicarse a un caso concreto. El criterio interpretativo que precede al método de interpretación debería ser el criterio principista, ya que permite introducir a lo técnicamente legal, los valores y principios jurídicos del derecho tributario y del derecho en general.

En cuanto a los métodos de interpretación admitidos por el derecho en materia tributaria, no son excluyentes ni existe uno que prevalezca sobre el otro, ya que pueden utilizarse uno o varios conjuntamente para esclarecer el significado de la ley y obtener una conclusión valida y sustentable.

Finalmente, nuestro derecho tributario no admite la analogía ni las interpretaciones excesivas en cuanto a los elementos esenciales del tributo ni las desgravaciones tributarias, ya que esto vulnera el principio de legalidad; sin embargo, la analogía es admitida con referencia a otros elementos no esenciales para la definición de la materia imponible; y la desgravación tributaria se interpreta de forma restrictiva. 


\section{REFERENCIAS}

Araoz Villena, Luis Alberto. «La interpretación económica de las leyes tributarias y la calificación de los hechos imponibles por su contenido económico». Revista del Instituto Peruano de Derecho Tributario, n. ${ }^{\circ} 23$ (diciembre 1992): 65-80.

Barth, José Francisco. «Principios y normas en la concepción del derecho de Dworkin (comentarios a las observaciones críticas de Luis Prieto Sanchís)». Revista de Ciencias Jurídicas, n. ${ }^{\circ} 108$ (setiembre-diciembre 2005): 177-202. https://revistas. ucr.ac.cr/index.php/juridicas/article/view/9716/9162

Carvalho, Paulo de Barros. Curso de derecho tributario. Lima: Grijley, 2012.

Carvalho, Paulo de Barros. "La interpretacion en materia tributaria». Revista de Derecho, n. ${ }^{\circ} 4$ (enero 2009): 35-55. https://revistas.ucu.edu.uy/index.php/ revistadederecho/article/view/823/825

Carvalho, Paulo de Barros. «Principios y sobreprincipios en la interpretacion del Derecho». En Derecho Tributario: tópicos contemporáneos, editado por Jorge Bravo Cucci y Daniel Yacolca Estares, Lima: Grijley, 2011.

Cazorla Prieto, Luis María. Derecho financiero y tributario: parte general. Navarra: Thomson Reuter Arazandi, 2000.

Dworkin, Ronald. «The model of rules». University of Chicago Law Review 35, n. ${ }^{\circ}$ 1 (1967): 14-46. https://chicagounbound.uchicago.edu/cgi/viewcontent. cgi? article $=3553 \&$ context $=$ uclrev

Ferreiro Lapatza, José juan. Curso de derecho financiero español. Madrid: Marcial Pons, 1992.

Huamaní, Rosendo. Código tributario comentado, vol. 1. Lima: Jurista Editores, 2019.

Jarach, Dino. Curso superior de derecho tributario. Buenos Aires: Cima, 1957.

Mur Valdivia, Miguel. «Elementos para la interpretación de las normas tributarias». Revista del Instituto Peruano de Derecho Tributario, n. 24 (junio 1993): 49-56.

Peralta, Carlos E. «Tributación y derechos fundamentales, los principios constitucionales como límite al poder tributario: reflexiones a partir de los ordenamientos jurídicos de Brasil y Costa Rica». Revista de Ciencias Jurídicas, n. ${ }^{\circ} 138$ (setiembre-diciembre 2015): 89-134.

https:/ / revistas.ucr.ac.cr/index.php/juridicas/article/view/22824/23304 
Rivera Postigo, Fernando. Derecho tributario sustantivo. Lima: A\&B Servicio Gráfico, 1988.

Rubio Correa, Marcial. Interpretación de las normas tributarias. Lima: ARA Editores, 2003.

Rubio Correa, Marcial. El sistema jurídico: introducción al derecho. 10. ${ }^{a}$ ed. Lima: Fondo Editorial PUCP, 2011.

Rubio Correa, Marcial Antonio. Manual de razonamiento jurídico. Lima: Fondo Editorial de la PUCP, 2017.

Ruiz de Castilla Ponce de León, Francisco J. «Inmunidad, inafectación, exoneración, beneficios e incentivos tributarios». Foro Jurídico, n. ${ }^{\circ} 12$ (marzo 2013): 136-148. https://revistas.pucp.edu.pe/index.php/forojuridico/article/ view $/ 13808 / 14432$

Ruiz de Castilla, Francisco. Derecho tributario: temas básicos. Lima: Fondo Editorial PUCP. 2017. https://repositorio.pucp.edu.pe/index/bitstream/ handle/123456789/170670/11\%20Derecho\%20tributario\%20con\%20sello.pdf?fbc lid=IwAR2iaxm6skk2zUraENt_S-mL6BvjPmSZVxqdJ9V0ENTzMZgxf8-B1kHGQQ

Santos Flores, Israel. «La interpretacion de la norma tributaria». En Manual de derecho fiscal, coordinado por Gabriela Ríos Granados, 61-92. México: Universidad Nacional Autónoma de México, 2020. https://archivos.juridicas.unam.mx/ www/bjv/libros/13/6278/5a.pdf

Tarsitano, Alberto. «Interpretacion de la ley tributaria». En Tratado de tributacion, derecho tributario, vol. 1, dirigido por Horacio A. García Belsunce, 411-563. Buenos Aires: Astrea, 2003. http://albertotarsitano.com/ interpretacion/7interpretaciondelaleytributaria.pdf

Tarsitano, Alberto. «Teoría de la interpretación tributaria». En El tributo y su aplicación: perspectivas para el siglo XXI, tomo 1, coordinado por César García Novoa y Catalina Hoyos Jiménez, 851-877. Madrid: Marcial Pons, 2008. http://www. albertotarsitano.com/interpretacion/15teoriainterpretacion.pdf

Villegas, Héctor. Curso de finanzas, derecho financiero y tributario. Buenos Aires: Depalma, 1992.

Zolezzi Möller, Armando. «Interpretación de la norma tributaria: ¿en los beneficios tributarios in dubio contra fiscum o in dubio pro fiscum?» Análisis tributario, (2010).

Zuzunaga, Assereto \& Zegarra abogados. Conflictividad en cifras ZEA 2020. Lima: Zuzunaga, Assereto \& Zegarra abogados, 2020. 
Ángel Marco Chávez Gonzales

\section{Sobre el autor}

Doctorando en Política Fiscal y Sistema Tributario, máster en Derecho por Boston University, diplomado en Precios de Transferencia (tax certificate) por Leyden University (Holanda), abogado por la Pontificia Universidad Católica del Perú y bachiller en Contabilidad por la Universidad Ricardo Palma. Es profesor en la Universidad ESAN (Perú) y profesor de posgrado en la Universidad Nacional Mayor de San Marcos. Ha sido miembro de la Comisión Consultiva de Derecho Tributario del Colegio de Abogados de Lima. Asesor tributario. 